\title{
Erratum to: Dismissing return periods!
}

\section{Francesco Serinaldi}

\section{Erratum to: Stoch Environ Res Risk Assess \\ DOI 10.1007/s00477-014-0916-1}

Equations 12, 13, 14, 17, 18 and percentage values reported in the bottom panels of Fig. 2 were mistyped in the above paper. They should read

$p_{\mathrm{COND} 1}:=\mathbb{P}[V>v \mid U>u]=\frac{1-u-v+C(u, v)}{1-u}$,

$$
\begin{aligned}
& p_{\mathrm{COND} 2}:=\mathbb{P}[V>v \mid U \leq u]=1-\frac{C(u, v)}{u} \\
& p_{\mathrm{COND} 3}:=\mathbb{P}[V>v \mid U=u]=1-\frac{\partial C(u, v)}{\partial u} \\
& p_{\mathrm{OR}} \geq \max \left\{p_{X}, p_{Y}\right\} \geq \min \left\{p_{X}, p_{Y}\right\} \geq p_{\mathrm{AND}} \\
& \mathcal{T}_{\mathrm{OR}} \leq \min \left\{\mathcal{T}_{X}, \mathcal{T}_{Y}\right\} \leq \max \left\{\mathcal{T}_{X}, \mathcal{T}_{Y}\right\} \leq \mathcal{T}_{\mathrm{AND}}
\end{aligned}
$$

The online version of the original article can be found under doi:10.1007/s00477-014-0916-1.

F. Serinaldi $(\bowtie)$

School of Civil Engineering and Geosciences, Newcastle

University, Newcastle Upon Tyne NE1 7RU, UK

e-mail: francesco.serinaldi@newcastle.ac.uk

F. Serinaldi

Willis Research Network, 51 Lime St., London EC3M 7DQ, UK 
Fig. 2 Similar to Fig. 1, but showing 1000 pairs $(u, v)$ simulated from a Gumbel copula. Each panel highlights the sets of pairs falling within the domains where each probability $\left(p_{\mathrm{AND}}, p_{\mathrm{K}}\right.$, etc.) is defined (grey circles and filled circles), and the subsets of pairs fulfilling the condition related to each type of probability (filled circles)
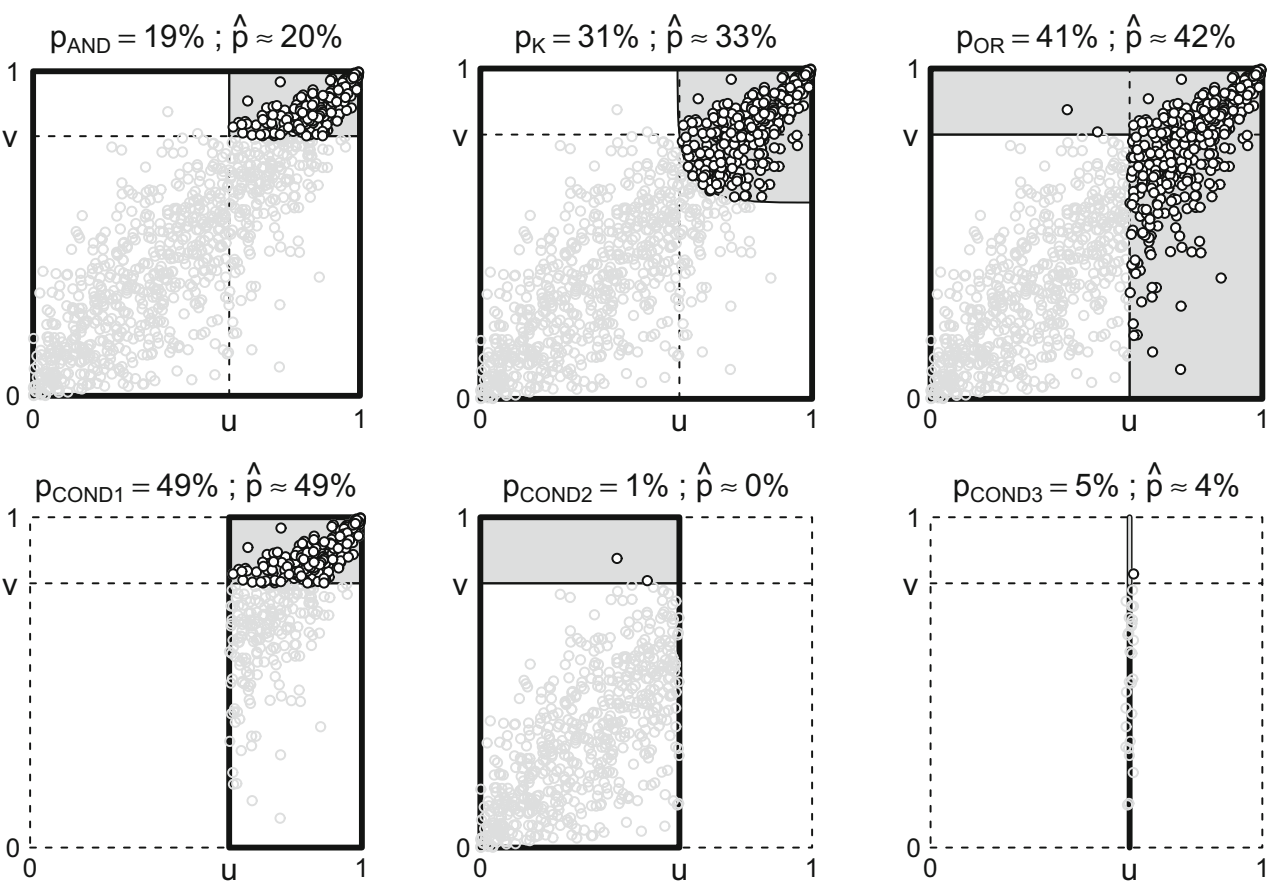